Volume 97, Number 5, September-Oetober 1992

Journal of Research of the National Institute of Standards and Technology

[J. Res. Natl. Inst. Stand. Technol. 97, 609 (1992)]

\title{
Errata
}

\section{Erratum: Optical Calibration of a Submicrometer Magnification Standard}

\author{
Jon Geist, Barbara Belzer, \\ Mary Lou Miller, and \\ Peter Roitman \\ National Institute of Standards \\ and Technology, \\ Gaithersburg, MD 20899
}

[J. Res. Natl. Inst. Stand. Technol. Volume 97, Number 2, March-April 1992, p. 267]

The figures over figure captions 1 and 3 should be interchanged. 